\title{
INSTRUCTIONS FOR AUTHORS
}

Manuscripts must be original, in clear English, and not currently under consideration for publication elsewhere. Two copies should be submitted-including one on airmail paper-in double-spaced typing on one side only of consecutively numbered pages of uniform size not more than $28 \mathrm{~cm}$ in length, leaving adequate margins. Survey and research papers should preferably be between 3,000 and 6,000 words in length and in no case exceed 8,000 words (including references etc.). Other contributions should not normally exceed 2,000 words, and those of more than half that length or three typed pages should be suitably subdivided with a brief heading to each section. Primary sub-headings in all papers should be centred, whereas any secondary ones should be brought out to the left-hand margin. Footnotes are, in general, deprecated except when inserted for editorial exposition. Headings of items in the sections Conferences \& Meetings and Reviews \& Notices must be in the style of the Journal-the former naming the occasion, place, and dates, and the latter complete with preliminary and other page totals, then indication of any illustrations, all three dimensions in metric, price, and date of publication (which should normally be not earlier than the preceding calendar year). The optimum length in both these categories is $300-500$ words, though double the latter may be approached for highly pertinent works of outstanding importance.

Style of Writing should be direct and concise, with punctuation etc. according to Collins's Authors' and Printers' Dictionary and spellings according to the Oxford English Dictionary. Dates should be in the form ' 1 March 1974' and single quotes should normally be used throughout. Any symbols or abbreviations employed should be the conventional ones, with omission of all unnecessary full stops (periods). If other than metric units are used, the metric equivalents must be inserted after them in parentheses. Submissions should be as neat and 'clean' as possible, and checked meticulously for errors and inconsistencies; always keep a fully corrected copy for reference in editorial correspondence or in case of loss of the original.

Tables are to be included in the main body of the manuscript, numbered consecutively with roman numerals, and appropriately headed. They should be kept as simple and short as possible, though longer Appendixes may exceptionally be allowed. All illustrationswhether photographs, drawings, or graphs-are to be numbered in a single sequence as 'Fig. 1', 'Fig. 2', etc., and so referred to in the text. Each must be clearly captioned, with acknowledgement of source when necessary, the captions being typed consecutively at the end of the paper (after the References).

Scientific Names of plant and animal genera, subgenera, species, and lower taxa, need to be underlined for italic, specific and lower epithets being written with a 'small' initial letter; the initials of precise (but not group) English and other vernacular names should, however, be capitalized. Nomenclature should be in accordance with the appropriate international code, and the publishing authority may if desired be given the first time a name is mentioned, though in that event consistency should be maintained with other names throughout the paper. Ecological and other scientific terms should either follow reasonably standardized usage or be defined the first time they are employed in a paper.

Submission of manuscripts should be by mid-December, mid-March, mid-June, and mid-September, for the Spring, Summer, Autumn, and Winter issues, respectively, the absolute deadline (particularly for short communications and brief news etc. items) being 1 January, 1 April, $1 \mathrm{July}$, and 1 October. As, however, considerable 'preediting' and correspondence are commonly necessary before an accepted paper is ready to go to the printer, submission should be considerably earlier to give a reasonable chance of publication in the issue of the following season if space allows. All refereeing is strictly confidential unless a referee agrees to the release of his or her identity through the Editor.

Titles of all papers should be as short as possible, inter alia for use as running heads. Those of research and survey papers are to be followed by the names of the author or authors (including preferred given name in full and any further initial or initials, and followed by indications of earned higher degrees and where obtained). Thereafter comes an indication of academic or other allegiance and/or senior post and full address underlined for italic. Instead of the customary Abstract at the beginning, a SUMMARY is required at the end of each paper to recapitulate and emphasize its main points. This should preferably not exceed about 350 words and follow any Acknowledgements. Short communications do not need a Summary and the 'signature' and address of their author or authors should be placed at the end.

Literature References are treated according to the Harvard System with some modifications. Thus in the body of the text they are cited by naming the author (or authors connected with an ampersand if two, or with et al. replacing all names after the first if more than two) and indicating the year of publication in parentheses: e.g. '(Smith, 1973)' or 'according to Smith (1973)'. References should be cited as 'in press' (not by date) only when already accepted by a journal, which should be named. Whereas in short communications any references may if desired be given in parentheses in the text, normally - and always in longer papers-they are to be collected together in a list headed 'References', alphabetically arranged by [first] authors' surnames but unnumbered, at the end of the paper. There, all authors' names and at least initials are required, followed by the date of publication (in parentheses), and then the full title of the paper (with capitalization of the initials only of precise names, but italicization of 'Latin' ones) or book (underlined for italic, and with capitalization of initials of all nouns and other 'major' words). There follows the title of the periodical, underlined for italic and given in full or contracted consistently, then the volume number in arabic (with number of part closed up in parentheses if desired), then the page-spread in the form 'pp. 321-5', and finally an indication of 'illustr.' (if it is). For books, the bare name of the publisher and place or places of publication are given, followed by full details of pages in the form of e.g. ': xvii +294 pp., illustr.' (if it is). In symposium volumes the page-spread of the individual paper should be given before 'in' and then the title of the book, which is subsequently to be treated as such with page-spread etc. Examples are to be found in any issue of this Journal or of Biological Conservation. Authors must ensure that their references are accurately cited: the Editor will be apt to refer back any which appear incorrect or are incomplete.

Illustrations are welcomed in limited numbers when really vivid and meaningful. Submission of single copies will suffice when necessary but all must be identified by at least the [first] author's surname and then figure number lightly pencilled on the back. Maps and other line drawings should be in a form ready for reproduction without redrawing, with stencilled or printed lettering and lined or largedotted shading, and suitable for reduction either to $8.1 \mathrm{~cm}$ (singlecolumn) or occasionally $16.7 \mathrm{~cm}$ (double-column) width. Photographs should normally be black-and-white glossy prints showing clear details and adequate contrast. The scale of all illustrations must be indicated if not evident, taking any reduction into account. Return of originals if desired should be indicated clearly but cannot be guaranteed, though a reminder when proofs are returned should be a safeguard. Costs of coloured illustrations can be quoted for. Proofs will be sent in duplicate to the author (or the first-named alone if more than one) of each paper or signed short communication (but not book review). They will be accompanied by a gummed addressed label for speedy return to the Editor, who reserves the right to 'pass for press' if authors' corrections are not received in time. A form for ordering extra offprints (see below), or reprints with special covers, will be enclosed with the proofs, and, together with a cheque for the appropriate amount (made out to 'The Foundation for Environmental Conservation'), should be returned with the corrected proof to the Editor who will collect such items for transmission to the proper quarters. In cases of plural authorship, authors receiving proofs are asked to check with their co-authors concerning corrections and ordering of separates. In view of the extremely high and ever-rising costs of printing, and particularly of altering set pages, it is regretted that only necessary corrections can be made in proof, although exceptionally, suggestions for alterations or brief additions may be entertained by the Editor.

Separates (50 free offprints, run off at the time of printing) will be sent to the author (or first-named if more than one) of each signed paper or short communication (but not conference report or book review). Additional offprints or, if preferred, special reprints with printed covers, may be ordered at the prices indicated on the form accompanying the proofs (see last paragraph above). Questions regarding separates, such as of conference reports or book reviews, possible loss, quotations for especially large orders or coloured illustrations, etc., should be addressed to the printer: Imprimerie du Journal de Genève, 20 rue F.-Dussaud, 1211 Geneva 8, Switzerland. The Editor wishes to indicate his availability for consultation but to emphasize that the more closely the above instructions are adhered to in the preparation of a manuscript, the speedier will be its consideration and, on acceptance, publication. 


\section{CONTENTS}

Editorials: Biospheric Stability and the Stratosphere . . . . . . . . . . . . . . . . . . 81

The Turning-point: Towards a New Ideology? . . . . . . . . . . . . . . . . . . . . 81

Progress or Catastrophe: Whither Our World? by Maurice F. Strong . . . . . . . . . . . . . . . . . . . 83

Inland Waterways-A New Envircnmental Dimension, by Frederic Doerflinger . . . . . . . . . . . . . . . 89

Industrial Development and Wildlife Conservation, by John G. Kelcey ． . . . . . . . . . . . . . . . . . . . 99

Pressures on Australian Rain-forests, by Professor Ian Douglas . . . . . . . . . . . . . . . . . . . . . . . 109

Objective and Subjective Judgements in Environmental Impact Analysis, by Dr William H. Matthews . . . . . 121

Guideline Principles to Govern the Importation of Hoofed Animals, by Professor George. A. Petrides . . . . . . . 133

Determination of the Priorities of 'Actors' in the Framework of Environmental Management, by Dr Michael G. Royston \& Joseph C. Perkowski . . . . . . . . . . . . . . . . . . . . . . . . . .

Range Expansion and Environmental Impress of the Introduced Walking Catfish in the United States, by Professor Walter R. Courtenay Jr \& Woodard W. Miley II

Short Communications : reports, comments, news, notes

Sir Julian Huxley, 1887-1975. . . . . . . . . . 88

Workshop Report on Manatee Research, by Dr

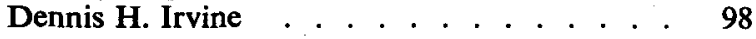

Bioregions: Towards Bioregional Strategy for Human Cultures, by Allen Van Newkirk . . . . . 108

Disease Hazards Associated with Bird Importations, by Professor Marshall Laird \& Dr Harry Hoogstraal ..............

The Real Crisis Behind the 'Food Crisis', by Justin Blackwelder ..............

Environmental Study in Algeria-Sience or Fashion?

by M. Amine Damerdji ........

The Desert Fishes Council, by Professor Robert Rush Miller . . . . . . . . . . . . 135
Surveys of British Amphibians and Their Habitats, by Dr Trevor J. C. Beebee . . . . . . . . . 136

Synergism of Insecticides by Herbicides Under Various Environmental Conditions, Professor E. P. Lichtenstein, T. T. Liang \& B. N. Anderegg . . 148

Chao Chong, Thailand's Pilot Project in Nature Education, by Klaus Berkmüller . . . . . . . . 149

Conferences \& Meetings : Reports by Phyllis BarclaySmith, Brian Yandell, Dr Raymond F. Dasmann, Professor Makoto Numata, Professor Sidney J. Holt, Dr Samir I. Ghabbour, and Nicholas Polunin

Reviews \& Notices: including reviews by Professor Harold S. Johnston, Peter F. R. Jackson, and Dr Samir I. Ghabbour; list of Other Books etc. Received 1973-74 . . . . . . . . . . 155

(C) 1975 The Foundation for Environmental Conservation, 15 Chemin F.-Lehmann, 1218 GrandSaConnex, Geneva, Switzerland.

All rights reserved. No part of this publication may be reproduced, stored in a retrieval system, or transmitted, in any form or by any means-electronic, mechanical, photocopying, recording, or otherwise-without permission in writing from the Editor or the copyright owners.

Printed in Switzerland by Imprimerie du Journal de Genève, 20 Rue F.-Dussaud, 1211 Geneva 8. 